\title{
ilkögretim Ögrencilerinin Bilişüstü Yetilerinin Matematik Akademik Başarılarına Cinsiyete ve Sınıf Düzeyine Göre İncelenmesi
}

\section{An Analysis of Elementary School Students' Metacognitive Skills in Relation to Some Variables}

\section{Nur SIRMACI ${ }^{*}$ \\ Fatih TAŞ}

Öz. Bu araştırmanın amacı, ilköğretim öğrencilerinin matematik dersine yönelik bilişüstü yetilerinin matematik akademik başarılarına cinsiyete ve sınıf düzeyine göre farklılaşıp farklılaşmadığını incelemektir. Araştırma Erzurum ili merkezinde 404 ilköğretim öğrencisi üzerinde gerçekleştirilmiştir. Öğrencilerin 187'i kı,217'si erkek öğrencidir. Bu Çalışmada Ubuz ve Aydın tarafından Türkçe'ye uyarlanarak geçerliliği ve güvenilirliği Türk kültüründe test edilmiş bilişüstü yeti anketi kullanılmıştır. Bu anket "Bilişin Bilgisi" ve "Bilişin Düzenlenmesi" olmak üzere iki boyuttan oluşmaktadır. Çalışmada veriler araştırmacılar tarafından, farkıı ilköğretim okullarına gidilerek bu anket yoluyla toplanmıştır. Matematik akademik başarısını belirlemek amacıyla öğrencilerden anket üzerine 1. dönem karne notlarının, cinsiyet ve sınıf bilgilerinin yazılması istenmiştir. Matematik karne notları 111-5" arasında yazılmış, değerlendirme bu aralıklar üzerinden yapılmıştır. Verilerin analizinde SPSS 16 paket programı kullanıımıştır. Çalışmada bilişüstü yetiler ile matematik akademik başarısı, cinsiyet ve sınıf düzeyleri arasında anlamlı ilişki bulunmuştur. Matematik başarıları arttıkça bilişüstü yetilerinin de arttığı gözlenmiştir.

Anahtar Kelimeler: Bilişüstü yeti, matematik başarısı, cinsiyet ve sınıf düzeyi.

Abstract. The purpose of this study is to analyze whether the effects of elementary school students' metacognitive skills for mathematics vary according to their mathematical academic achievement levels, genders, and grades. The research was conducted on 404 elementary school students in Erzurum. All the students, 187 were girls and 217 were boys. In the study a metacognitive skill scale adapted to Turkish and the validity and reliability of which were tested in Turkish context by Ubuz and Aydın was used. This scale consists of two dimensions called "Knowledge of Cognition" and "Regulation of Cognition". In the study, the data were collected through this scale by the researchers going to different elementary schools. In order to determine the students' academic achievements, they were asked to write their first-semester school report scores on the scale form besides their gender, and grades. Mathematics scores ranged between " 1 and 5 " and the analysis was made on this range. SPSS 16 package program was used in the analysis of the data. In the study a significant relationship was found between metacognitive skills and mathematical academic achievement, genders, and grades. It was evidenced that as the mathematical achievement levels increase, so do the metacognitive skills.

Keywords: Metacognitive skill, mathematical academic achievement, gender, and grade.
Toplumsal Mesaj. Bilişüstü yetiler öğrencilerin bilişsel süreçlerinin farkında olmaları, bilişsel süreçlerini düşünmeleri ve düşünmeyi düşünmelerini içerir. Bireylerin, edindikleri bilginin ne olduğundan çok bilgiyi edinme yolları üzerinde durulmaktadır. Dolayısıyla bireylerde aranan nitelikler arasında kişinin kendi düşünme süreçlerinin farkında olması ve bu süreçleri kontrol edebilmesi yer almaktadır.

Public Interest Statement. Metacognitive skills involve students' awareness of their cognitive processes, reflection on their cognitive processes, and thinking on their own thinking. In recent years, it has been observed that how individuals learn rather than what they learn has been focused on. In other words, not what individuals learn but how they learn gains inıportance.

\footnotetext{
${ }_{* \star}^{*}$ Türkmenistan, nsirmaci@yahoo.com 


\section{GiRiş}

Öğretim süreci içerisinde son yıllarda bireylerin, edindikleri bilginin ne olduğundan daha çok bilgiyi edinme yollarının neler olduğu üzerinde durulmaya başlandığı görülmektedir. Artık yeni yüzyılın paradigması bireylerin ne öğrendikleri değil, "öğrenmeyi öğrenme" yollarını bilip bilmedikleridir (Çakıroğlu, 2007). Bednarik, Keionen (2011) e göre bireyin öğrenme sürecinin farkında olması öğrenme performansını etkiler. Diğer yandan Özsoy (2007) kendi zihinsel faaliyetlerini izleyebilme, gözlemleyebilme ve öğrenmenin özdenetimi gibi yeteneklerin üstbiliş becerilerini oluşturduğunu bildirmektedir.

Üstbiliş kavramının Flavell tarafından eğitim alanına getirildiği görülür. üstbiliş, bireyin öğrenme sürecinin farkında olması, bu süreçte kontrol, izleme ve bilişsel süreçleri düzenleme olarak ifade edilir. (Brown, 1987; Flavell, 1987; Nelson ve Narens, 1996). Flavell (1979), üstbiliş ve biliş kontrolünü dörtlü bir sınıflama yaparak modellemiştir. Bunlar: üstbilişsel bilgi, üstbilişsel deneyim, hedefler ve stratejilerdir. Schunk'a (2009)'a göre, üstbiliş, yüksek düzeyli biliştir. Özsoy (2007)'a göre üstbiliş, öğrenme sürecinin farkında olma, planlama ve stratejiler seçme, öğrenme sürecını izleme, hatalarını düzeltebilme, kullandığı stratejilerin işe yarayıp yaramadığını kontrol edebilme, gerektiğinde öğrenme yöntemini ve stratejilerini değiştirebilme gibi yeteneklere sahip olmayı da beraberinde getirir. Üstbiliş bilgi ve becerilerinin kişinin kendi öğrenmesinin farkında olacabileceğini ve gerektiğinde değerlendirme yaparak öğrenme eksikliklerini belirleyebileceğini belirtmiştir. Bireyin kendi bilgisi hakkında bilgi sahibi olması, süreç içinde bunu kontrol edebilmesi ve gerekli düzenlemeleri yapabilmesini içermektedir. Flavell (1976) üstbilişi şu şekilde açıklamaktadır; Üstbiliş bireyin, bilişsel işlemleri ve çıktıları veya onlarla ilgili herhangi bir şey hakkındaki bilgisini ifade eder. Eğer A işlemini öğrenmenin B işlemini öğrenmekten daha fazla zor olduğunun farkındaysam; eğer C'nin doğru olduğunu kabul etmeden önce onu tekrar kontrol etmek zorunda olduğumu hissediyorsam; eğer unutabilme ihtimalim olduğu için D'ye daha iyi çalışmam gerektiğini hissediyorsam; eğer E'nin doğru olup olmadı̆̆ını anlamak için birisine sormayı düşünüyorsam üstbilişle meşgul oluyorum demektir (Flavell, 1976; Akt: Çakıroğlu, 2007a).

Hacker (1998)'a göre üstbiliş ve biliş, işlev bakımından da birbirinden ayrılmaktadır. Biliş, sözü geçen kavramlarla ilişkili dinamik bir olgu olarak kabul edildiğinde "Bilişsel süreç" olarak ele alınabilir. Bu anlamda bilişsel süreç, "algı, dikkat etme, yorumlama, anlama ve hatırlama gibi zihinde gerçekleşen içsel süreçleri ifade eder (Bacanlı, 2003: 182). Bilişin işlevi, problemleri çözmek, iyi bir sona ulaşmak için bilişsel girişimler önermektir. Üstbilişinki ise bireyin problem çözmedeki bilisel sürecini düzenlemek veya üstlenilen bir işi yönetmektir. Bu fark bireyin anlamadığının farkına varması, çevrede anlamasını olumsuz yönde etkileyen faktörleri engellemek için motive olması ve kavramasını artırmak için bilinçli bir şekilde belleğini kullanması biçiminde örneklendirilebilir. Üstbiliş stratejileri biliş süreçlerini izleme ve düzenleme için kullanılır. Akpunar (2011)'a göre üstbiliş, kendi başına anlam kazanan bir terim olmayıp, biliş bağlamında anlamlandırılan bir kavramdır. Her ne kadar bilişin "üstü" ve "ötesi" olarak ifade edilse de, üstbiliş, aslında bilişin bir parçası olarak ifade edilebilmektedir. Dolayısıyla üstbilişi, içinde çıktığı düşünülen biliten ayrı olarak, izole bir şekilde ele almak doğru değildir. Öğrenme süresince, problem çözme, anlama, akıl yürütme ve bellek gibi bilişsel süreçler üstbilişe örnek verilebilir. Bunun yanında çeşitli araştırmalarda üstbiliş ve zekâ arasında ilişki kurularak problem çözme ya da diğer entelektüel becerilerin kullanımında üstbilişsel stratejilerin önemi vurgulanmıştır. (Hertzog ve Robinson, 2005; Sternberg, 2005; Sternberg ve Ben-Zeev, 2001). Bu stratejiler, bireyin bilişsel etkinliklerinde kullandığı ardışık süreçlerdir. Bu süreçler, öğrenmeyi düzenleme ve denetlemeye yardımcı olurken bilişsel uygulamaları planlama ve izlemeyi de içine alır (Özsoy, 2007).

Bilişüstü kavramı bilişin bilgisi ve bilişin düzenlenmesi olarak iki temel bileşende ele alınmaktadır (Schraw ve Dennisoni 1994; Nietfeld, Cao ve Osborne, 2005; Akt: Yıldız ve Ergin, 2007). Bilişin bilgisi; öğrenenin kendi kendisiyle öğrenme durumu arasındaki uyum ile ilgili bilgilerdir. Öğrenenin kendi bilişiyle ve farkındalı̆̆ıla ilgilidir. Bilişin bilgisini demeçsel bilgi, yöntemsel bilgi ve 
koşulsal bilgi oluşturur. Bilişin düzenlenmesi ise; problemleri çözmek için öğrenci tarafından kullanılan kendini düzenleme süreçleri ile ilgilidir. Burada bilişüstü süreçler planlama, izleme, ölçme, revize etme ve değerlendirme olarak ayrılmaktadır (Flavell, 1987; Stewart ve Landine, 1995; Dirkes, 1985). Planlama, izleme ve düzenleme belli başlı bilişüstü stratejilerdir. Planlama stratejisi, öğrencilerin çalışmaları için hedef belirlemeleri, bir metni okumadan önce gözden geçirmeleri veya bir problemle ilgili iş analizi yapmaları gibi etkinlikleri içerir (Alcı, Erden ve Baykal, 2010).

Diger yandan bazı araştırmalarda ise başarı düzeyi ile üstbiliş becerileri arasında anlamlı ilişki bulunduğu belirlenmiş̧ir (Deseote ve Roeyers, 2002; Case, Harris ve Graham, 1992). Üstbiliş ve akademik başarı arasındaki ilişkiyi ortaya koyan araştırmalar, üstbiliş öğretimi yoluyla başarının yükseltilmesine yönelik deneysel araştırmaları da beraberinde getirmiştir. Bu amaçla yapılan araştırmaların sonunda da üstbiliş yeteneklerini geliştirmeye yönelik öğretim süreçleri uygulanan çocukların başarı düzeylerinde olumlu yönde ve anlamlı artışlar olduğu ortaya çıkmıştır (McDougall ve Brady, 1998; Naglieri ve Johnson, 2000; Teong, 2002; Victor, 2004; Özsoy, 2007; Çakıroglu, 2007b).

Araştırmalar matematik dersinde başarısı yüksek öğrencilerin, başarıları düşük öğrencilere göre bilişüstü stratejilerini daha etkili kullandıklarını ortaya koymuştur (Desoete, 2001). Benzer olarak Şen (2012) de bilişüstü yetiler ile matematik başarısı açısından ortaya çıkan duruma bakıldı̆̆ında, öğrencilerin matematik ders başarısı ile ölçülen bilişüstü yetileri arasında pozitif yönlü orta düzeyde anlamlı bir ilişki bulunmuştur. Öğrencilerin problem çözme stratejilerini kullanmada esnek olmalarına, daha zor problemlere yönelmelerine ve hangi stratejilerin hangi durumlarda daha uygun olduğunu belirlemelerine üstbiliş yardımcı olur (Ormrod, 2003).

\subsection{Araştırmanın Amacı}

Araştırmanın amacı, ilköğretim 6, 7 ve 8. sınıfta okuyan öğrencilerin bilişüstü yetilerinin farklı değişkenler açısından incelenmesidir. Bu amaç doğrultusunda aşağıdaki sorulara cevap aranmıştır:

1. Öğrencilerin cinsiyetlerine göre bilişüstü yetileri açısından aralarında anlamlı bir fark var mıdır?

2. Öğrencilerin sınıf düzeylerine göre bilişüstü yetileri açısından aralarında anlamlı bir fark var mıdır?

3. Öğrencilerin bilişüstü yetilerine göre matematik dersindeki başarıları arasında anlamlı bir ilişki var mıdır?

\section{YÖNTEM}

Bu çalışmada tarama modeli kullanılmıştır. Tarama modelleri mevcut olan durumu var olduğu şekliyle betimlemeyi amaçlayan araştırma yaklaşımlarıdır. Burada araştırmaya konu olan durum, olay, birey ya da nesne kendi koşulları içerisinde ve olduğu gibi tanımlanmaya çalışılır (Karasar, 2005).

\section{1 Çalışma Grubu}

Araştırma Erzurum ilinden random yoluyla seçilmiş dört ilköğretim okulu ve bu okullarda altı, yedi ve sekizinci sınıfta öğrenim gören öğrenciler üzerinde yürütülmüştür.

\subsection{Veri Toplama Aracı ve Verilerin Analizi}

Araştırmada Aydın ve Ubuz tarafından geliştirilen, geçerlik ve güvenirlik çalışması yapılmış, "Bilişüstü Yeti Anketi" kullanılmıştır. Geliştirilen anket beşli likert tipi olup, "bilişin bilgisi" ve "bilişin düzenlenmesi" olmak üzere iki boyuttan oluşmaktadır. Bilişin bilgisi için geçerlik-güvenirlik çalışması sonucunda Cronbach-alpha iç tutarlılık değeri. 75, bilişin düzenlenmesi için. 79 olarak ve madde toplam korelasyonu ise .40 'dan yüksek bulunmuştur. Ayrıca anket üzerine cinsiyet bilgisi ve matematik dersine ait birinci dönem karne notlarının da yazılması istenmiştir. Matematik karne notları "1-5" arasında yazılmış ve değerlendirme bu aralıklar üzerinden yapılmıştır. 


\subsection{Verilerin Analizi}

Verilerin analizinde SPSS 16.0 (Statistical Package for the Social Sciences) programı kullanılmıştır. Elde edilen veriler üzerinden frekans, yüzde değerleri, bağımsız örneklemler için t-testi ve tek yönlü varyans analizleri yapılmış, öğrencilerin bilişüstü yetileri ile matematik dersi başarısı arasındaki ilişki Spearman Brown'un korelasyon katsayısı kullanılarak bakılmış ve bulgular kısmında tablolaştırılarak yorumlanmıştır.

\section{BULGULAR VE YORUMLAR}

Araştırmaya katılan sınıf düzeyleri, öğrenci sayılarına ve cinsiyetlerine göre Tablo 1'de gösterilmektedir.

Tablo 1. Öğrencilerin Sınıf Düzeyleri ve Cinsiyete Göre Dağılımları

\begin{tabular}{lccc}
\hline & Değişkenler & $f$ & $\%$ \\
\hline Sınıf & 6. Sınıf & 196 & 48 \\
Düzeyleri & 7. Sınıf & 108 & 27 \\
& 8. Sınıf & 100 & 25 \\
\hline Cinsiyet & Kız & 187 & 46 \\
& Erkek & 217 & 54 \\
\hline
\end{tabular}

Tablo 1 incelendiğinde, araştırmaya katılan sınıf türlerinden 6. Sınıf \%48 ile en fazla 7.ve 8. Sınıf birbirine yakın yüzdelerle araştırmaya katılmıştır. Araştırmaya katılan öğrencilerin yarısından fazlasının erkek öğrencilerden, yarıya yakınının da erkek öğrencilerden oluştuğu görülmektedir.

\section{1 Öğrencilerin cinsiyetlerine göre bilişüstü yetileri açısından aralarında anlamlı bir fark var mıdır?}

Araştırmaya katılan öğrencilerin cinsiyetlerine göre bilişüstü yetiler, bilişin bilgisi ve bilişin düzenlenmesi ile ilgili olarak bir farklılaşmanın olup olmadığı sorgulandığında elde edilen bulgular Tablo 2'de verilmiştir.

Tablo 2. Bilişüstü Yetiler ve Cinsiyet ilişkisi Dağılımı

\begin{tabular}{llcccccc}
\hline & Cinsiyet & $\mathrm{n}$ & $\overline{\mathrm{X}}$ & $\mathrm{ss}$ & $\mathrm{t}$ & $\mathrm{sd}$ & $\mathrm{p}$ \\
\hline \multirow{2}{*}{ Bilişin Bilgisi } & Kız & 187 & 4.24 & .53 & \multirow{2}{*}{2.595} & \multirow{2}{*}{402} & .05 \\
& Erkek & 217 & 4.09 & .63 & & & \\
\hline \multirow{2}{*}{ Bilişin } & Kız & 187 & 3.86 & .64 & \multirow{2}{*}{3.019} & \multirow{2}{*}{402} & .05 \\
Düzenlenmesi & Erkek & 217 & 3.65 & .72 & & & \\
\hline \multirow{2}{*}{ Bilişüstü Yeti } & Kız & 187 & 4.04 & .54 & \multirow{2}{*}{3.077} & \multirow{2}{*}{402} & .05 \\
& Erkek & 217 & 3.86 & .62 & & & \\
\hline
\end{tabular}

Tablo 2'deki değerler incelendiğinde kız ve erkek öğrencilerin bilişin bilgisi, bilişin düzenlenmesi ve bilişüstü yeti puan ortalamalarına ilişkin $t$ değerlerinin tümü $p<0.05$ önem düzeyinde anlamlı bulunmuştur. Bu bulgular kız ve erkek öğrencilerin bilişin bilgisi, bilişin düzenlenmesi ve bilişüstü yeti açısından aralarında fark olduğunu göstermektedir. Tablonun incelenmesi sürdürüldüğünde bilişin bilgisi, bilişin düzenlenmesi ve bilişüstü yeti açısından farkların kız öğrenciler lehine anlamlı olduğu görülmüştür. Sonuç olarak kız öğrencilerin daha başarılı oldukları söylenebilir.

\section{2 Öğrencilerin sınıf düzeylerine göre bilişüstü yetileri açısından aralarında anlamlı bir fark var midır?}

Araştırmaya katılan öğrencilerin sınıf düzeylerine göre bilişüstü yetiler, bilişin bilgisi ve bilişin düzenlenmesi ile ilgili olarak bir farklılaşmanın olup olmadığı sorgulandığında elde edilen bulgular Tablo 3 ve Tablo 4 'te verilmiştir. Bilişüstü yetiler ile sınıf düzeyleri, ortalamaları ve standart sapmaları Tablo 3'de verilmiştir. 
Tablo 3. Bilişüstü Yetiler ve Sınıf Düzeyi Puanları

\begin{tabular}{lllll}
\hline & Sınıf Düzeyi & $\mathrm{n}$ & $\overline{\mathrm{X}}$ & ss \\
\hline \multirow{3}{*}{ Bilişin Bilgisi } & 6. Sınıf & 196 & 4.27 & .59 \\
& 7.Sınıf & 108 & 4.14 & .51 \\
& 8.Sınıf & 100 & 3.96 & .62 \\
\hline \multirow{2}{*}{ Bilişin } & 6. Sınıf & 196 & 3.85 & .71 \\
Düzenlenmesi & 7. Sınıf & 108 & 3.78 & .59 \\
& 8.Sınıf & 100 & 3.51 & .69 \\
\hline \multirow{3}{*}{ Bilişüstü Yeti } & 6. Sınıf & 196 & 4.05 & .61 \\
& 7.Sınıf & 108 & 3.95 & .49 \\
& 8.Sınıf & 100 & 3.72 & .61 \\
\hline
\end{tabular}

6. sınıfta öğrenim gören öğrencilerin bilişin bilgisi ortalamalarının $(X=4.27)$, bilişin düzenlenmesi $(X=3.85)$ olup diğer sınıf düzeylerinde öğrenim gören öğrencilere göre daha yüksek olduğu gözlenmiştir. Toplam puan bakımından da 6. sınıfta öğrenim gören öğrencilerin bilişüstü yetilerinin ortalaması $(X=4.05) 7$ ve 8 . sınıf öğrencilerine göre daha yüksek olduğu gözlenmiştir. Öğrencilerin devam etikleri sınıfın, sınıf düzeyine göre bilişüstü yetilerine ilişkin puanları arasında anlamlı bir farkın olup olmadığı, Tek Yönlü varyans analizi ile test edilmiş ve sonuçları Tablo 4'de gösterilmiştir.

Tablo 4. Bilişüstü Yetiler ve Sınıf Düzeyi Arasındaki Illişki

\begin{tabular}{llccccc}
\hline & & $\begin{array}{c}\text { Karelerin } \\
\text { Toplamı }\end{array}$ & sd & $\begin{array}{c}\text { Karelerin } \\
\text { Ortalaması }\end{array}$ & $\mathrm{f}$ & $\mathrm{p}$ \\
\hline \multirow{3}{*}{ Bilişin Bilgisi } & Gruplar Arası & 6.594 & 2 & 31.297 & & \\
& Gruplar İçi & 136.568 & 401 & .341 & 9.681 & .00 \\
& Toplam & 143.162 & 403 & & & \\
\hline \multirow{2}{*}{ Bilişin } & Gruplar Arası & 7.064 & 2 & 3.846 & & \\
Düzenlenmesi & Gruplar İçi & 186.278 & 401 & .465 & 8.279 & .00 \\
& Toplam & 193.332 & 403 & & & \\
\hline \multirow{3}{*}{ Bilişüstü Yeti } & Gruplar Arası & 6.594 & 2 & 31.532 & & \\
& Gruplar İçi & 136.568 & 401 & .342 & 10.337 & .00 \\
& Toplam & 143.162 & 403 & & & \\
\hline
\end{tabular}

Tablo 4 incelendiğinde, yapılan tek yönlü varyans analizi sonuçlarına göre öğrencilerin devam etikleri sınıf düzeyine göre bilişin bilgileri, bilişin düzenlenmesi ve genel olarak bilişüstü yetilerine ilişkin puanlar arasında anlamlı bir fark olduğu gözlenmiştir. Bu farklılığın hangi gruplar arasında olduğunu görmek için Sheffe testi yapılmış ve farklılığın altıncı sınıf ile sekizinci sınıf arasında olduğu anlaşılmıştır.

\section{3 Öğrencilerin bilişüstü yetilerine göre matematik dersindeki başarıları arasında anlamlı bir ilişki var mıdır?}

Öğrencilerin bilişüstü yetileri ile matematik dersindeki başarıları arasında anlamlı bir ilişki olup olmadığı Pearson korelasyon katsayısı ile incelendiğinde sonuçları Tablo 5 'de gösterilmiştir.

Tablo 5. Bilişüstü Yetiler ve Matematik Başarısı Arasındaki Iliş̧ki

\begin{tabular}{lccc}
\hline & Bilişin Bilgisi & Bilişin Düzenlenmesi & Bilişüstü Yeti \\
\hline $\begin{array}{l}\text { Matematik Akademik } \\
\text { Başarısı }\end{array}$ & .521 & .341 & .458 \\
\hline
\end{tabular}

Öğrencilerin matematik ders başarısı ile ölçülen bilişin bilgileri arasında pozitif yönlü orta düzeyde anlamlı bir ilişki bulunmuştur $(r=0.521 \quad p<0.01)$. Bir başka deyişle, öğrencilerin matematik ders 
başarıları arttıkça bilişin bilgileri de artmaktadır veya öğrencilerin matematik ders başarıları düştükçe bilişin bilgileri de azalmaktadır. Doğrusal bir ilişki söz konusudur.

Öğrencilerin matematik ders başarısı ile ölçülen bilişin düzenlenmesi puanları arasında da pozitif yönlü orta düzeyde anlamlı bir ilişki bulunmuştur ( $r=0.347 p<0.01)$. Bu bağlamda öğrencilerin matematik ders başarıları arttıkça bilişin düzenlenmesi puanları da artmaktadır veya öğrencilerin matematik ders başarıları düştükçe bilişin düzenlenmesi puanları da azalmaktadır. Doğrusal bir iliş̧i söz konusudur.

Bilişüstü yetilere genel olarak bakıldığında; öğrencilerin matematik ders başarısı ile ölçülen bilişüstü yetileri arasında pozitif yönlü orta düzeyde anlamlı bir iliş̧i bulunmuştur ( $r=0.458$ $\mathrm{p}$ <0.01). Bir başka deyiş̧le, öğrencilerin matematik ders başarıları arttıkça bilişüstü yetileri de artmaktadır veya öğrencilerin matematik ders başarıları düştükçe bilişüstü yetileri de azalmaktadır. Doğrusal bir ilişki söz konusudur.

\section{TARTIŞMA VE SONUÇ}

illköğretim 6,7 ve 8. sınıf öğrencilerinin bilişüstü yetilerinin cinsiyet, sınıf düzeyi ve matematik dersi başarısı açısından ele alındığı araştırmada genel olarak şu sonuçlara ulaşılmıştır. Bilişüstü yetiler açısından kız öğrenciler, erkek öğrencilere göre daha başarılı bulunmuştur. Benzer araştırma sonuçları incelendiğinde bulguları destekleyen araştırmalara rastlanmıştır. Şen (2012), Alcı ve Altun (2007) Peklaj ve Pecjak, (2002), Miller (2000) kızların erkeklere göre matematik dersinde bilişüstü becerilerinin daha yüksek olduğunu yaptığı çalışmasında açıklamıştır. Bu sonuçlara göre kız öğrencilerin öğrenme surecinin farkında olma, planlama ve stratejiler seçme, öğrenme surecini izleme, hatalarını düzeltebilme, kontrol edebilme, gerektiğinde öğrenme yöntemini ve stratejilerini değiştirebilme gibi yeteneklere erkek öğrencilerden daha fazla sahip olduğu söylenebilir.

Sınıf düzeyi ile bilişüstü yetilere bakıldığında, toplam puan bakımından 6. sınıfta öğrenim gören öğrencilerin bilişüstü yetilerinin $(X=4.05) 7$ ve 8 . sınıfta öğrenim gören öğrencilere göre daha yüksek olduğu gözlenmiştir. Koç ve diğerleri (2011)'e göre sınıf düzeyi artıkça bilişüstü yetilerin azaldığı bulgusu desteklenmiştir. Buna gerekçe olarak öğrencilerin 6. sınıftan 8. sınıfa doğru çoktan seçmeli sınavlarla daha çok değerlendirilmeleri, dört seçenekten birini tercih etmeleri planlama, izleme, kontrol etme ve değerlendirme gibi bilişüstü becerileri kullanmalarını azaltmış olabilir.

Bilişüstü yetiler ile matematik başarısı açısından ortaya çıkan duruma bakıldığında ise; öğrencilerin matematik ders başarısı ile ölçülen bilişüstü yetileri arasında pozitif yönlü orta düzeyde anlamlı bir ilişki bulunmuştur $(r=0.324 \mathrm{p}<0.01)$. Üstbilis ve akademik basarı arasındaki ilişsiyi ortaya koyan araştırmalar, üstbiliş öğretimi yoluyla başarının yükseltilebileceğini, olumlu yönde ve anlamlı artışlar olduğu ortaya çıkmıştır (Naglieri ve Johnson, 2000; Teong, 2002; Victor, 2004; Özsoy, 2007; Çakıroglu, 2007b). Matematik dersinin büyük bir bölümünü problem çözme süreci oluşturmakatdır. Bu süreçlerde üstbiliş stratejilerinin kullanılması matematik akademik başarısını artıracaktır. Araştırmanın bulgularını destekleyen Şen (2012) ye göre ortaöğretim öğrencilerinin üstbiliş yetileri ile matematik başarıları arasında doğrusal bir ilişki söz konusudur.

\section{5. ÖNERILER}

Öğrencilerin öğrenme sürecinin farkında olmaları, nasıl öğrendikleri hakkında bilgi sahibi olmaları sağlanmalıdır.

Bilişüstü yetilerin okul öncesinden yükseköğretime kadar farklı okul kademelerinde incelenmesi, elde edilen sonuçlara göre öğretim programlarının ve rol model olan öğretmenlerin destek ve yönlendirici olması önemlidir.

Üsbiliş stratejilerinin matematik ve diğer dersilerde kullanılabilmesi için imkanlar yaratılmalıdır. Öğretmenlerin, problem çözme sürecinde öğrencilere rehberlik etmeleri, onların üstbiliş yetilerini artırmaları için gerekli önlemlerin alınmasını sağlamaları gerekmektedir. 


\section{Kaynakça}

Akpunar, B. (2011) Biliş ve Üstbiliş Kavramlarının Zihin Felsefesi Açısından Analizi. Lnternational Periodical for the Languages, Literature and History of Turkish or Turkic, 6(4), 353-365.

Alcı, B. ve Altun S. (2007). Lise Öğrencilerinin Matematik Dersine Yönelik Özdüzenleme ve Bilişüstü Becerileri, Cinsiyete, Sınıfa ve Alanlara Göre Farkılış̧makta Mıdır? Ç.Ü. Sosyal Bilimler Enstitüsü Dergisi, 16(1), 33-44.

Alcı, B., Erden, M. ve Baykal, A. (2010). Üniversite Öğrencilerinin Matematik Başarıları ile Algıladıkları Problem Çözme Becerileri, Özyeterlik Algıları, Bilişüstü Özdüzenleme Staretejileri ve ÖSS Sayısal Puanları Arasındaki Açıklayıcı ve Yordayıcı Iliş̧kiler Örüntüsü. Boğaziçi Üniversitesi Eğitim Dergisi, 25(2), 53-68.

Bacanlı, H. (2003). Gelişim ve Öğrenme. Ankara: Nobel Yayın Dağıtım

Pihlainen-Bednarik, K. ve Keinonen, T. (2011). Sixth Graders' Understanding of Their Own Learning: A Case Study in Environmental Education Course. International Journal of Environmental and Science Education, 6(1), 59-78.

Brown, A. (1987). Metacognition, Executive Control, Self-Regulation, and Other More Mysterious Mechanisms. Metacognition, Motivation, and Understanding, 65-116.

Case, L .P., Harris, K. R. ve Graham, S. (1992). Improving the Mathematical Problem Solving of Students with Learning Disa Bilities: Self-Regulated Strategy Development. The Journal of Special Education, 26, 1-19.

Çakıroglu, A. (2007a). Üstbiliş. Türkiye Sosyal Arastırmalar Dergisi, 11(2), 21-27.

Çakıroğlu, A. (2007b). Üstbilişsel Strateji Kullanımının Okuduğunu Anlama Düzeyi Düşük Öğrencilerde Erişi Artırımına Etkisi. Yayımlanmamış Doktora Tezi, Gazi Üniversitesi, Ankara.

Desoete, A. (2001). Metagognition and Mathematical Problem Solving in Grade 3. Journal of Learning Disabilities. 34 (5), 435-449

Desoete, A. ve Roeyers, H. (2002). Off-Line Metacognition - A Domain-Specific Retardation in Young Children with Learning Disabilities. Learning Disability Quarterly, 25, 123-139.

Dirkes, M. A. (1985). Metacognition: Students in Charge of Their Thinking. Roeper Review, 8(2), 96100.

Flavell, J. (1979). Metacognition and Cognitive Monitoring:A New Area of Cognitive- Developmenta L Inquiry. American Psychologist, 34, 906-911.

Flavell, J. H. (1987). Speculations About the Nature and Development of Metacognition. En FE Weinert \& RH Kluwe (Ed.), Metacognition, Motivation and Understanding (Pp. 21-29). Hillside, New Jersey: Lawrence Erlbaum Associates.

Hacker, D. J. (2001). Metacognition: Definitions and Empirical Foundations [On-Line Report]. Memphis. TN: The University of Memphis.

Hacker, D. J., Dunlosky, J. ve Graesser, A. C. (Ed.). (1998). Metacognition in Educational Theory and Practice. Routledge.

Hertzog, C. ve Robinson, A. E. (2005). Metacognition and Lntelligence. In: O. Wilhelm \& R.W. Engle (Ed) ,Handbook of Understanding and Measuring Lntelligence. London: Sage Publications.

Karasar, N. (2005). Bilimsel Araştırma Yöntemi. Ankara: Nobel Yayım Dağıtım.

Mcdougall, D. ve Brady, M. P. (1998). Lnitiating and Fading Self-Management Interventions to Increase Math Fluency in General Education Classes. Exceptional Children, 64, 151- 166.

Miller, J. W. (2000). Exploring The Source of Self Regulated Learning: The Influence of Internal And External Comparisons. Journal of Lnstructional Pyschology, 27, 47-52. 
Naglieri, J. A. ve Johnson, D. (2000). Effectiveness of A Cognitive Strategy Intervention in Improving Aritmethic Computation Based on the Pass Theory. Journal of Learning Disabilities, 35, 591597.

Nelson, T. O. ve Narens, L. (1996). Why Lnvestigate Metacognition? In J. Metcalfe \& A. P. Shimamura (Ed.). Metacognition. Cambrige, MA: Mit Press.

Ormrod, J. E. (2003). Educational Psychology: Developing Learners (4th Ed.). Upper River Saddle, NJ: Pearson.

Özsoy, G. (2007). Illköğretim beşinci sınıfta üstbiliş stratejileri öğretiminin problem çözme başarısına etkisi. Yayımlanmamış Yüksek Lisans Tezi. Ankara: Gazi Üniversitesi Eğitim Bilimleri Enstitüsü.

Özsoy, G. (2008). Üstbiliş. Türk Eğitim Bilimleri Dergisi, 6(4), 713-740.

Peklaj, C. Ve Pecjak, S., (2002). Differences in Students' Self-Regulated Learning According to Their Achievement and Sex. Studia Psychology, 44, 29-43.

Schunk, D. H. (2009). Öğrenme Teorileri. Çev. Muzaffer Şahin) Ankara: Nobel Yayıncılık.

Şen, Ş. H. (2012). Ortaöğretim Öğrencilerinin Bilişüstü Yetileri Kullanma Durumlarının Bazı Değişkenler Açısından Incelenmesi. Journal of Educatioanl and Instructional Studies in the World, 2(1), 2146-7463.

Sternberg, R. J. (2005). The Triarchic Theory of Successful Lntelligence. In: D. P. Flanagan \& P. L. Harrison (Ed.\}, Contemporary Lntellectual Assessment (Pp: 103-119). New York: The Guilford Press.

Sternberg, R. J. ve Ben-Zeev, T. (2001). Complex Cognition: The Psychology of Human Thought. Oxford University Press.

Stewart, J. ve Landine, J. (1995). Study Skills From A Metacognitive Perspective. Guidance \& Counselling, 11(1), 16-20.

Teong, S. K. (2003). The Effect of Metacognitive Training on Mathematical Word-Problem Solving. Journal of Computer Assisted Learning, 19(1), 46-55.

Victor, A. M. (2004). The Effects of Metacognitive Instruction on the Planning and Academic Achievement of First and Second Grade Children. Unpublished Doctoral Dissertation, II Graduate College of the Illinois Istitute of Technology, Chicago.

Yıldız, E. ve Ömer, E. (2007) . Bilişüstü ve Fen Öğretimi. Gazi Eğitim Fakültesi Dergisi, 27(3), 175-196. 


\section{Extended Summary}

\section{Purpose of the Study}

The purpose of the study is to analyze 6th, 7th, and 8th grade students' metacognitive skills in relation to some variables. For this purpose, answers were sought for the following questions:

1. Are there significant differences between the students by gender with respect to their metacognitive skills?

2. Are there significant differences between the students by grade with respect to their metacognitive skills?

3. Are there significant differences between the students by their academic achievement levels with respect to their metacognitive skills?

\section{Method}

In this study, a survey was used. Surveys are the research approaches aiming to describe the current situation as it is. Here, the phenomenon, case, individual, or object under investigation is aimed to be identified in its own conditions and as it is (Karasar, 2005).

\section{Data Collection Instrument and Data Analysis}

The "Metacognitive Skill Scale" developed by Aydın and Ubuz and analyzed for its validity and reliability was used. The instrument is a five-point Likert scale and consists of two dimensions as "knowledge of cognition" and "regulation of cognition". in the validity- reliability analysis, the Cronbach-alpha intemal consistency for "knowledge of cognition" was found to be .75 and for "regulation of cognition" .79; and, items total correlation was found to be higher than .40. in addition, the participants were asked to write down their gender and first-semester mathematical report scores on the scale form. The mathematical scores were written in a range from 1 to 5 and the the analyses were carried out on this scale.

In data analysis, SPSS 16.0 (Statistical Package for the Social Sciences) programme was used. The data were dealt with through analyses of frequencies, percentages, independent samples t-tests, and oneway anova; and, the relationship between students' metacognitive skills and mathematical academic achievement was found by using Spearman Brown's correlation coeffıciencies; and, the fındings were given tables and then interpreted.

\section{Discussion and Conclusion}

In the study in which elementary school 6th, 7th, and 8th grade students' metacognitive skills were dealt with in relation to their gender, grade, and mathematical academic achievement levels, the following findings were obtained.

The female students were found to be more successful than the male participants with respect to their metacognitive skills. When the findings were compared to the results of similar studies, some parallel fındings were evidenced. Şen (2012), Alcı and Altun (2007) Peklaj and Pecjak, (2002), and Miller (2000) reported in their studies that females had higher levels of metacognitive skills in mathematics courses than the males did. According to these results, it can claimed that female students have higher levels of skills of being aware of the leaming process, planning, choosing strategies, monitoring the learning process, correcting one's own mistakes, and, when necessary, changing learning styles and strategies than male students.

When metacognitive skills were analyzed in relation to grades, it was observed that means of metacognitive skills scores of 6 th grade students $(X=4.05)$ were higher than means of 7 th an 8 th grade students. In Koç et al. (2011), the finding that as grade levels of students increase, their levels of metacognitive skills decrease was supported. As a reason for this, the facts that from grade 6 to grade 8 , the students are evaluated through multiple-choice tests more and that they choose the right among four options might cause them to weaken their planning, monitoring, controlling, and evaluating skills. 
When the relation between metalingguistic skills and mathematical achievement is examined, a medium-level significant positive correlation was found between these two variables $(r=0.324$ $p<0.01$ ). The studies which revealed the relationship between metacognition and academic achievement reported that achievement can be reinforced by metacognitive training and positive and significant increases might be gained (Naglieri \& Johnson, 2000; Teong, 2002; Victor, 2004; Özsoy, 2007; Çakıroglu, 2007b). A great part of mathematics consists of problem solving processes. In these processes, use of metacognitive skills will increase mathematical academic achievement. According to Şen (2012) who supported the fındings of this study, there is a linear correlation between the metacognitive skills and mathematical academic achievements of students. 